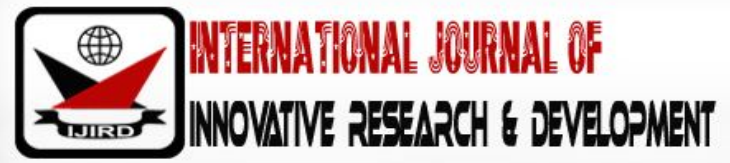

ISSN 2278 - 0211 (Online)

\section{Antimicrobial Activities and Phytochemical Screening of Citrus Aurantifoila (Lime) Leaf Extracts and Fruit Juice on Some Microorganisms}

\author{
Ugwu, C. C \\ Assistant Lecturer, Department of Applied Microbiology and Brewing, \\ Enugu State University of Science and Technology, Nigeria \\ Mbah-Omeje, K. N \\ Assistant Lecturer, Department of Applied Microbiology and Brewing, \\ Enugu State University of Science and Technology, Nigeria \\ Ezeugwu, R. I \\ Lecturer, Department of Applied Microbiology and Brewing, \\ Enugu State University of Science and Technology, Nigeria \\ Onuorah, S. C \\ Senior Lecturer, Nnamdi Azikiwe University, Nigeria \\ Agbo, M. C \\ Assistant Lecturer, Department of Microbiology, University of Nigeria, Nigeria
}

\begin{abstract}
:
This work studies the antimicrobial activities and phytochemical constituents of Citrus aurantifoila (lime) leaf extracts and fruit juice on some microorganisms. The antimicrobial activities and minimum inhibitory/ minimum bacteriocidal/ fungicidal concentrations (MIC/ MBC/ MFC) of ethanolic, methanolic and aqueous extracts of Citrus aurantifolia leaves and fruits juice were determined on some pathogenic microorganisms namely: Staphylococcus aureus, Escherichia coli, Psuedomonas aeruginosa, Pseudomonas aeruginosa (ATCC 27853) and Trichophyton rubrum using agar well diffusion method. The methanolic extract was found to show more activity than the ethanolic and aqueous extract on all the isolates except for E.coli that showed resistance to all the extracts. The inhibition zone diameters (IZD) of methanol, ethanol and aqueous extracts ranged between 5 and $23 \mathrm{~mm}, 4$ and $14 \mathrm{~mm}$ and 4 and $11 \mathrm{~mm}$ respectively. The MICs of ethanolic extracts were 0.76 $\mathrm{mg} / \mathrm{ml}$ for Staphylococcus aureus, $200 \mathrm{mg} / \mathrm{ml}$ for Escherichia coli, $1.56 \mathrm{mg} / \mathrm{ml}$ for Pseudomonas aeruginosa, $0.76 \mathrm{mg} / \mathrm{ml}$ for Pseudomonas aeruginosa (ATCC 27853) and $50 \mathrm{mg} / \mathrm{ml}$ for Trichophyton rubrum. The MICs of methanolic extract were 0.76 $\mathrm{mg} / \mathrm{ml}$ for Staphylococcus aureus, $200 \mathrm{mg} / \mathrm{ml}$ for Escherichia coli, $1.56 \mathrm{mg} / \mathrm{ml}$ for Pseudomonas aeruginosa, $0.76 \mathrm{mg} / \mathrm{ml}$ for Pseudomonas aeruginosa (ATCC 27853) and $25 \mathrm{mg} / \mathrm{ml}$ for Trichophyton rubrum. The MICs of aqueous extract were $0.76 \mathrm{mg} / \mathrm{ml}$ for Staphylococcus aureus, $200 \mathrm{mg} / \mathrm{ml}$ for Escherichia coli, $1.56 \mathrm{mg} / \mathrm{ml}$ for Psuedomonas aeruginosa and Psuedomonas aeruginosa (ATCC 27853) and $100 \mathrm{mg} / \mathrm{ml}$ for Trichophyton rubrum. The MBC/ MFC ranged from $3.125 \mathrm{mg} / \mathrm{ml}$ to $12.5 \mathrm{mg} / \mathrm{ml}$ for all organisms tested. The standard control antibiotic/antifungal (ciprofloxacin/ fluconazole) showed comparable results with the plant extracts. The phytochemical analysis carried out on the plant extracts revealed the presence of saponins, flavonoids, steroids, alkaloids, tannins, glycosides and reducing sugars. Statistical analyses showed that there were significant differences in the antimicrobial activities of each extract on the test organisms. The presence of these phytochemicals supports the use of this plant as antimicrobial agent and thus can be used in the treatment of some infections caused by these tested pathogenic microorganisms.
\end{abstract}

Keywords: Citrus aurantifoila, antimicrobial activities, phytochemical constituents, plant extract, inhibition zone diameter

\section{Introduction}

The use of plants in curing and treatment of illnesses have deep roots in man's history (Mata et al., 1994; Grabley and Thiericke, 1999). According to the World Health Organization, a medicinal plant is any plant in which one or more of its organs contain substances that can be used for the synthesis of useful drugs (WHO, 1977). Medicinal plants contain biologically active chemical substances such as saponins, tannins, alkaloids and other chemicals (Sofowora, 1996) which have curative 
properties. These complex chemical substances of different composition are found as secondary metabolites in one or more of these plants (Kayode and Kayode, 2011). These medicinal plants are used in the treatment of malaria, diarrhea, burns, gonorrhea, stomach disorders and other infectious diseases (Ibukun et al., 2007).

Citrus aurantifolia (lime) is a small, densely and irregular branched tree with short, sharp spines. It is characterized by greenish-yellow fruits which is either sour or sweet naturally. Sour limes possess a greater sugar and citric acid content than lemons and feature as acidic and tart taste (Bina et al., 2010). The fruits and leaves have medicinal properties. There are several species of citrus trees whose fruits are called limes; including the Key limes (Citrus aurantifolia), Persian lime, Kaffir lime, and dessert lime. This plant is rich in carbohydrate, sugar, soluble and insoluble fibre, sodium, vitamins, minerals, fatty acids, amino acids, etc. (Ibukun et al., 2007). It also contains unique flavonoid compounds that have antioxidant and anticancer properties. These flavonoids have been shown to stop cell division in many cancer cell lines and are perhaps most interesting for their antibiotics effects (Tomotake, 2006).

In Nigeria, lime is used to suppress stomach ache. The juice has been found to be excellent cough relieving mixture when added to sugar, palm oil or honey. The rind is burnt in some homes especially by Yorubas and used as insecticides against mosquitoes. The mesocarp is also used as a very good facial scrub and helps in prevention of pimples due to its cleansing action on the skin (Onyeagba et al.,2004). Citric acid, the major organic acid in the lime juice was found to be responsible for inhibiting the growth of Vibrios which causes illness through consumption of contaminated food and water. Thus, used as disinfectant and inhibitor of Vibrio cholera in drinking water in areas lacking water treatment plants (Daquino and Teves, 1994). It also exhibits bioactive activities for colds, fevers, sore throats, bronchitis and asthma (Khan et al., 2012).

In recent years, drug resistance to human pathogenic bacteria has been commonly reported from all over the world (Aibinu et al., 2003; Aibinu et al., 2004; Grosvenor et al., 1995; David, 1997; Saxena,1997). This is as a result of indiscriminate use of antimicrobials which led to the emergence of new bacterial strains that are multi - resistance (Robin et al., 1998). Therefore, alternative antimicrobial strategies are urgently needed and thus this situation has led to a re - evaluation of the therapeutic use of ancient remedies such as plants. Being new, such compounds may not have the problem of microbial resistance. These plants are easily available and cheaper than the conventional drugs. Presently, nearly $30 \%$ or more of the modern pharmacological drugs are derived directly or indirectly from plants and their extracts (Murugesan et al., 2011; Jabeen et al., 2007; Banson, 2009). As a result of rapid increase of antibiotic resistance in bacteria of medicinal importance, there is a constant need for new and effective therapeutic agents. This work therefore evaluates the antimicrobial activities and phytochemical constituents of Citrus aurantifolia leaf and juice on some selected organisms using different extracting solvents.

\section{Materials and Methods}

\subsection{Collection of Plant Materials}

Fresh Citrus aurantifolia leaves were collected from Nsukka in Enugu, Nigeria. The leaves were identified in the Department of Applied Biology and Biotechnology, ESUT. These leaves were then washed severally to remove dirt, dried in shade at room temperature, ground to powder and stored in a sterile air tight container.

Lime fruits that were free from decay were washed with distilled water to remove dirt and further sterilized with ethanol to remove any form of contaminant. The fruits were cut with sterile knife and aseptically the juice was extracted and kept in a sterile container in a temperature of $4^{\circ} \mathrm{C}$ to $8^{\circ} \mathrm{C}$.

\subsection{Preparation of Extracts}

Fifty grams of Citrus aurantifolia leaf powder was soaked separately in $500 \mathrm{ml}$ of methanol, ethanol and distilled water respectively for $24 \mathrm{~h}$ and centrifuged at $3000 \mathrm{rpm}$ (revolutions per minute) to enable proper diffusion of the active ingredients as described by Akinnibosun and Edionwe (2015). After that, the contents were filtered using muslin cloth and filtered again using Whatman's filter paper No 1. The filtrates were evaporated separately in a water bath and then used to check the antimicrobial activities of some selected pathogenic microorganism.

\subsection{Isolation and Selection of the Test Organisms}

The organisms used for the research comprise of one Gram-positive bacterium (Staphylococcus aureus); two Gramnegative bacteria (Pseudomonas aeruginosa and Escherichia coli) and one fungus (Trichophyton rubrum). The bacteria were obtained from the clinical laboratory of Parklane Teaching Hospital Enugu, Nigeria and the fungus were isolated from the head of a child infected with Trichophyton rubrum which is the most common organism that causes ringworm.

\subsection{Characterization and Identification of Trichophyton Rubrum}

Typical isolates of T. rubrum are whitish in colour and cottony on the surface of Sabour and dextrose agar. The colony underside is usually red, although some isolates appear more yellowish and others more brownish. This fungus can be identified by its teardrop or peg-shaped microconidia. The colony was further identified using lactophenol cotton blue staining method. 


\subsection{Lacto phenol Cotton Blue Staining}

A solution of lacto phenol cotton blue was prepared as described by Onuorah et al. (2016). Using a straight wire, a fragment of the fungal isolate was placed on a clean grease-free slide. Two drops of the lactophenol cotton blue solution were added and the stain allowed to penetrate. The slide was then viewed under the microscope.

\subsection{Standardization of Inoculum}

Test organisms were subculture onto fresh plates of nutrient agar for $24 \mathrm{~h}$ and Sabour and dextrose agar for 5-7 days at $37^{\circ} \mathrm{C}$ for bacteria and fungi respectively as described by Ibukun et al. (2007). Colonies from these plates were suspended in nutrient broth and Sabour and broth to a turbidity matching $0.5 \mathrm{McFarland}$ standard $\left(10^{8} \mathrm{cfu} / \mathrm{ml}\right)$ for bacteria and fungi respectively.

\subsection{Dilution of the extracts}

The stored extracts were reconstituted using dimethyl sulfoxide (DMSO) to obtain extracts of several concentrations $200,100,50,25,12.5,6.25,3.125$ and $1.56 \mathrm{mg} / \mathrm{ml}$ and stored at $4^{0}$ Cprior to determination of the minimum inhibitory concentration.

\subsection{Determination of Antimicrobial Activities of the Plant Extract}

The antimicrobial screening of the ethanol, methanol, and aqueous extracts were carried out using agar well diffusion method. Several dilutions of the crude extract of the lime juice were made as described by Dingle et al. (1953). The dilutions are as follows:

- $75 \%$-- $75 \mathrm{ml}$ of fruit juice and $25 \mathrm{ml}$ of $\mathrm{H}_{2} \mathrm{O}$

- $50 \%--50 \mathrm{ml}$ of fruit juice and $50 \mathrm{ml}$ of $\mathrm{H}_{2} \mathrm{O}$

- $25 \%-25 \mathrm{ml}$ of fruit juice and $75 \mathrm{ml}$ of $\mathrm{H}_{2} \mathrm{O}$

- $5 \%$-- $5 \mathrm{ml}$ of fruit juice and $95 \mathrm{ml}$ of $\mathrm{H}_{2} \mathrm{O}$.

The antimicrobial activities of these dilutions were assayed on the selected organisms by agar well diffusion method.

2.9. Determination of Minimum Inhibitory Concentration (MIC) and Minimum Bacteriocidal/ Fungicidal Concentration $(\mathrm{MBC} / \mathrm{MFC})$

Minimum inhibitory concentration was determined by agar well diffusion method as described by Ogata et al. (2000). The plates containing Mueller Hinton agar medium were spread with $0.1 \mathrm{ml}$ of the bacterial in oculum. Wells $(6 \mathrm{~mm}$ in diameter) were cut from agar plates using a sterilized stainless-steel borer and wells were filled with $0.1 \mathrm{ml}$ of each extract. The plates were incubated at $3^{\circ} \mathrm{C}$ for $24 \mathrm{~h}$ and the diameter of resultant zone of inhibition was measured. The least concentration that inhibited the growth of microorganism was termed the MC. The MBC/ MFC was determined by inoculating $0.1 \mathrm{ml}$ of each of test organisms into the tube that contained the different dilutions of the plant extracts. At the end of incubation for $24 \mathrm{~h}$ and 2-4 days respectively for bacteria and fungi, the plate that showed no growth of organism is termed MBC or MFC.

\subsection{Antibiotics Sensitivity Test}

A known antibiotic/ antifungal (ciprofloxacin/ fluconazole) were used to test bacteria and fungi respectively on its susceptibility to antibiotics and antifungal. These were employed to compare and contrast the antimicrobial activities of the plant extract.

\subsection{Phytochemical Evaluation of the Plant Extract}

Phytochemical analysis was carried out using standard protocol for determination of the following phytoconstituents: alkaloids, flavonoids, saponins, tannins, glycoside, reducing sugar and steroids as described by Odebiyi et al. (1978). The tests are as follows:

\subsubsection{Test for alkaloids}

Five grams of the evaporated extract was boiled with $5 \mathrm{ml}$ of dilute $\mathrm{HCl}$ in a water bath for 5 minutes. The mixture was cooled and filtered. And the filtrate was subjected to alkaloids test using Drag end off's reagent. alkaloids.

The filtrate was treated with Drag end off's reagent. The formation of a red precipitate indicates the presence of

\subsubsection{Test for Flavonoids}

Three grams of the extract was treated with ethyl acetate solution, heated in water bath for 1 minute. The mixture was cooled and filtered. The filtrate was shaken with 1\% Aluminium chloride solution and left for 10 minutes. The formation of yellow colouration indicates the presence of flavonoids. 


\subsubsection{Test for Saponins}

One gram of the extract was boiled with $5 \mathrm{ml}$ of distilled water for 5 minutes. The content was filtered while hot and the filtrate was treated with few drops of olive oil and vigorously shaken. The formation of emulsion indicates the presence of saponins.

\subsubsection{Test for Tannins}

Two grams of the evaporated extract was boiled with $45 \%$ ethanol for 5 minutes. The mixture was cooled and filtered. Then, the filtrates were then treated with few drops of lead acetate solution. The formation of gelatinous precipitate indicates the presence of tannins.

\subsubsection{Test for Glycosides}

One gram of the evaporated extract was boiled with $15 \mathrm{ml}$ of distilled water for 5 minutes in a water bath. The mixture was cooled and filtered. $0.2 \mathrm{ml}$ of Fehling's solution A and B was added to $5 \mathrm{ml}$ of the filtrate and further boiled for 2 minutes in a water bath. The formation of a brick red colouration indicates the presence of glycosides.

\subsubsection{Test for Reducing Sugars}

The plant extract was treated with Fehling's solution (A and B) in a test tube. The colour change from deep blue to brick red indicates the presence of reducing sugar.

\subsubsection{Test for Steroids}

Two $\mathrm{ml}$ each of concentrated sulphuric acid $\left(\mathrm{H}_{2} \mathrm{SO}_{4}\right)$ and acetic anhydride were poured into $5 \mathrm{ml}$ each of the aqueous extract samples. The colour changed from violet which indicates the presence of steroids.

\subsection{Statistical Analysis}

All data collected were analyzed using one-way ANOVA.

\section{Results}

\subsection{Determination of Antimicrobial Activities of the Plant Extract}

The antimicrobial activities of Citrus aurantifolia plant extracts were determined on the test organisms. It was observed that the methanolic extract had the highest effect on the test organisms followed by ethanolic and aqueous extracts. In methanolic extract, Pseudomonas aeruginosa showed the highest susceptibility (23 $\mathrm{mm}$ ) while Trichophyton rubrum showed the least susceptibility $(9 \mathrm{~mm})$ and E.coli showed resistance to the extract. In ethanolic extract, Staphylococcus aureus showed the highest susceptibility $(14 \mathrm{~mm})$ while Trichophyton rubrum showed the least susceptibility $(5 \mathrm{~mm})$ and E. coli showed resistance to the extract. In aqueous extract, Staphylococcus aureus showed highest susceptibility (11 mm) while Pseudomonas aeruginosa showed least susceptibility and E.coli and Trichophyton rubrum showed resistance to the extract.

The antimicrobial activity of Citrus aurantifolia fruit juice was carried out on Trichophyton rubrum. It was observed that the organism showed more susceptibility to the fruit juice when concentrated than when it has been diluted with distilled water. These are shown in tables 1, 2, 3 and 4.

\begin{tabular}{|c|c|c|c|c|c|c|c|c|c|}
\hline Test Organisms & \multicolumn{8}{|c|}{ Different Concentrations (Mg/ MI) / Zones Of Inhibition (Mm) } \\
& $\mathbf{2 0 0}$ & \multicolumn{10}{|c|}{$\mathbf{1 0 0} \mathbf{5 0}$} & $\mathbf{2 5}$ & $\mathbf{1 2 . 5}$ & $\mathbf{6 . 2 5}$ & $\mathbf{3 . 1 2 5} \mathbf{1 . 5 6}$ & $\mathbf{0 . 7 6}$ \\
\hline Staphylococcus aureus & 13 & 12 & 11 & 10 & 10 & 9 & 9 & 8 & 0.0 \\
\hline Escherichia coli & 0.0 & 0.0 & 0.0 & 0.0 & 0.0 & 0.0 & 0.0 & 0.0 & 0.0 \\
\hline Pseudomonas aeruginosa & 23 & 19 & 18 & 16 & 14 & 11 & 10 & 0.0 & 0.0 \\
\hline $\begin{array}{c}\text { Pseudomonas aeruginosa } \\
\text { (ATCC27853) }\end{array}$ & 22 & 13 & 13 & 12 & 11 & 10 & 9 & 8 & 0.0 \\
\hline Trichophyton rubrum & 9 & 7 & 5 & 0.0 & 0.0 & 0.0 & 0.0 & 0.0 & 0.0 \\
\hline
\end{tabular}

Table1: Antimicrobial Activities of Citrus Aurantifolia Methanolic Extract on Test Organisms 


\begin{tabular}{|c|c|c|c|c|c|c|c|c|c|c|}
\hline \multirow{2}{*}{ Test organisms } & \multicolumn{8}{|c|}{ Different concentrations (mg/ ml)/ Zones of inhibition (mm) } \\
\cline { 2 - 12 } & \multicolumn{2}{|c|}{200} & 100 & 50 & 25 & 12.5 & 6.25 & 3.125 & 1.56 & 0.76 \\
\hline Staphylococcus aureus & 14 & 11 & 10 & 9 & 7 & 6 & 5 & 0.0 & 0.0 \\
\hline Escherichia coli & 0.0 & 0.0 & 0.0 & 0.0 & 0.0 & 0.0 & 0.0 & 0.0 & 0.0 \\
\hline Pseudomonas aeruginosa & 10 & 9 & 8 & 7 & 5 & 5 & 5 & 0.0 & 0.0 \\
\hline $\begin{array}{c}\text { Pseudomonas } \\
\text { aeruginosa(ATCC27853) }\end{array}$ & 10 & 9 & 8 & 7 & 6 & 6 & 5 & 5 & 0.0 \\
\hline Trichophyton rubrum & 5 & 4 & 0.0 & 0.0 & 0.0 & 0.0 & 0.0 & 0.0 & 0.0 \\
\hline
\end{tabular}

Table 2: Antimicrobial Activities of Citrus Aurantifolia Ethanolic Extract on the Test Organisms

\begin{tabular}{|l|c|c|c|c|c|c|c|c|c|c|c|}
\hline \multirow{2}{*}{ Test organisms } & \multicolumn{7}{|c|}{ Different concentrations (mg/ ml)/ Zones of inhibition (mm) } \\
\cline { 2 - 12 } & 200 & 100 & 50 & 25 & 12.5 & 6.25 & 3.125 & 1.56 & 0.76 \\
\hline Staphylococcus aureus & 11 & 9 & 8 & 7 & 7 & 6 & 5 & 4 & 0.0 \\
\hline Escherichia coli & 0.0 & 0.0 & 0.0 & 0.0 & 0.0 & 0.0 & 0.0 & 0.0 & 0.0 \\
\hline Pseudomonas aeruginosa & 8 & 8 & 7 & 6 & 5 & 4 & 4 & 0.0 & 0.0 \\
\hline $\begin{array}{l}\text { Pseudomonas } \\
\text { aeruginosa(ATCC27853) }\end{array}$ & 9 & 8 & 7 & 7 & 4 & 4 & 4 & 0.0 & 0.0 \\
\hline Trichophyton rubrum & 0.0 & 0.0 & 0.0 & 0.0 & 0.0 & 0.0 & 0.0 & 0.0 & 0.0 \\
\hline
\end{tabular}

Table 3: Antimicrobial Activities of Citrus Aurantifolia Aqueous Extract on Test Organisms

\begin{tabular}{|c|c|c|c|c|c|}
\hline Test Organisms & \multicolumn{5}{|c|}{ Different percentage (\%)/ Zones of inhibition(mm) } \\
\hline & 100 & 75 & 50 & 25 & 5 \\
\hline Staphylococcus aureus & 16.0 & 9.0 & 6.0 & 0.0 & 0.0 \\
\hline Pseudomonas aeruginosa (ATCC 27853) & 13.0 & 10.0 & 8.0 & 0.0 & 0.0 \\
\hline Pseudomonas aeruginosa & 23.0 & 11.0 & 9.0 & 0.0 & 0.0 \\
\hline Escherichia coli & 16.0 & 10.0 & 6.0 & 0.0 & 0.0 \\
\hline Trichophyton rubrum & 24.0 & 0.0 & 0.0 & 0.0 & 0.0 \\
\hline
\end{tabular}

Table 4: Effect of Lime Juice Extract on Test Organisms

\subsection{Determination of Susceptibility of the Test Organisms Using Standard Antibiotics/ Antifungal}

Different concentrations of ciprofloxacin and fluconazole were used for bacteria and fungi respectively. It was observed that the bacteria and fungi showed more susceptibility to higher concentrations of standard antibiotics than the lower concentrations. This is shown in table 5.

\begin{tabular}{|c|c|c|c|c|c|}
\hline \multirow{2}{*}{ Test organisms } & \multicolumn{3}{|c|}{ Ciprofloxacin } & \multicolumn{2}{c|}{ Fluconazole } \\
& \multicolumn{2}{|c|}{ Different concentrations(mg/ ml) } & \multicolumn{2}{c|}{ Different concentrations(mg/ ml) } \\
\cline { 2 - 5 } & 200 & 100 & 50 & 100 & 50 \\
\hline Staphylococcus aureus & 22.0 & 20.0 & 15.0 & $\mathrm{ND}$ & ND \\
\hline Escherichia coli & 20.0 & 19.0 & 18.0 & $\mathrm{ND}$ & $\mathrm{ND}$ \\
\hline Pseudomonas aeruginosa & 15.0 & 12.0 & 10.0 & $\mathrm{ND}$ & $\mathrm{ND}$ \\
\hline Pseudomonas aeruginosa(ATCC 28753) & 17.0 & 15.0 & 10.0 & $\mathrm{ND}$ & ND \\
\hline Trichophyton rubrum & $\mathrm{ND}$ & $\mathrm{ND}$ & $\mathrm{ND}$ & 18.0 & 15.0 \\
\hline
\end{tabular}

Table 5: Zones of Inhibition (Mm) of Standard Antibiotic / Antifungal on Test Organisms

\subsection{Determination of Minimum Inhibitory Concentration of the Extract on the Test Organisms}

The minimum inhibitory concentration was assayed on the test organisms. It was observed that E. coli showed resistance to all the extracts thus, highest minimum inhibitory concentration $(200 \mathrm{mg} / \mathrm{ml})$ while least minimum inhibitory concentration was observed in Pseudomonas aeruginosa (ATCC 27853) 0.76mg/ ml. This is shown in table 6. 


\begin{tabular}{|c|c|c|c|}
\hline \multirow{2}{*}{ Test organisms } & \multicolumn{3}{|c|}{ Minimum inhibitory concentration (mg/ ml) } \\
\cline { 2 - 4 } & Ethanol & Methanol & Aqueous \\
\hline Staphylococcus aureus & 0.76 & 0.76 & 0.76 \\
\hline Escherichia coli & 200 & 200 & 200 \\
\hline Pseudomonas aeruginosa & 1.56 & 1.56 & 1.56 \\
\hline Pseudomonas aeruginosa(ATCC27853) & 0.76 & 0.76 & 0.76 \\
\hline Trichophyton rubrum & 50 & 25 & 100 \\
\hline
\end{tabular}

Table 6: Minimum Inhibitory Concentration of Citrus Aurantifolia Ethanolic, Methanolic, and Aqueous Extracts on Test Organisms

\subsection{Determination of Minimum Bacteriocidal / Fungicidal Concentrations of the Extract on the Test Organisms}

The minimum bacteriocidal/ fungicidal concentrations of the extract on the test organisms were determined. The highest minimum bactericidal concentration/ minimum fungicidal concentrations were observed in Pseudomonas aeruginosa (ATCC 27853) and Trichophyton srubrum. While E. coli showed the least minimum bactericidal concentration. This is shown in table 7.

\begin{tabular}{|c|c|c|c|}
\hline Test organisms & \multicolumn{3}{|c|}{ Minimum bactericidal concentration(MBC)/ MFC (mg/ ml) } \\
\hline & Ethanol & Methanol & Aqueous \\
\hline Staphylococcus aureus & 3.125 & 3.125 & 1.56 \\
\hline Escherichia coli & 0.0 & 0.0 & 0.0 \\
\hline Pseudomonas aeruginosa & 3.125 & 6.25 & 1.56 \\
\hline Pseudomonas aeruginosa(ATCC 27853) & 12.5 & 6.25 & 3.125 \\
\hline Trichophyton rubrum & 12.5 & 12.5 & 6.25 \\
\hline
\end{tabular}

Table 7: Minimum Bactericidal/ Fungicidal Concentrations of Citrus Aurantifolia Extracts on the Test Organisms

\subsection{Determination of Phytochemical Constituents of the Plant Extracts}

The phytochemical test carried out revealed that the aqueous extract contains all the phytochemicals; saponin, flavonoids, steroids, alkaloids, tannins, glycosides and reducing sugars while ethanol extract contains all the phytochemicals except steroids and the methanolic extract contains all other phytochemical except saponin and steroids. This is shown in table 8.

\begin{tabular}{|c|c|c|c|}
\hline Constituents & Aqueous extract & Ethanol extract & Methanol extract \\
\hline Saponin & + & + & - \\
\hline Flavonoids & + & + & + \\
\hline Steroids & + & - & + \\
\hline Alkaloids & + & + & + \\
\hline Tannins & + & + & + \\
\hline Glycosides & + & + & + \\
\hline Reducing sugars & + & + & + \\
\hline
\end{tabular}

Table 8: Phytochemical Constituents of Citrus Aurantifolia Using Different Extracting Solvents

\section{Discussion}

Antimicrobial resistance of pathogenic bacteria to current synthetic drugs has necessitated the investigation into new, safe, efficient and cost effective antimicrobial agents as alternative agents for controlling the infectious diseases (Khan et al., 2012). The extent of sensitivity of the test organisms to the plant extracts was assayed by measuring the zone of inhibition (ZOI) and Minimum bactericidal concentration/minimum fungicidal concentration (MBC/ MFC) produced by extracts on particular test organism for the estimation of potency of the extract after 24hours of incubation. Tables 1 to 3 showed the antimicrobial activities of Citrus aurantifolia leaf extract using different extracting solvents. The results of the study showed that the ethanolic, methanolic, and aqueous leaf extracts of Citrus aurantifolia inhibited the growth of all the isolates except for E. coli that showed resistance to all the extracts. The methanolic extract was found to be most effective against the test organisms than the other extracting solvents while aqueous extract showed the least effectiveness to the test organisms. Pseudomonas aeruginosa showed the highest susceptibility $(23 \mathrm{~mm})$ to C.aurantifolia methanolic extract, while Trichophyton rubrum showed the least susceptibility $(9 \mathrm{~mm})$ to this extract. This work is in agreement with the work of Akinnibosun and Edionwe, (2015) who stated that methanolic extract of C.aurantifolia leaf extracthave more activity on the tested organisms than other extracting solvents. This is also in agreement with the observations of Tshesche, (1970), who concluded that the stronger extraction capacity of methanol for C.aurantifolia could have been responsible for the higher antimicrobial activity. 
In ethanolic extract of the plant, higher antimicrobial activity was observed against Staphylococcus aureus (14 mm) and least activity was observed in Trichophyton rubrum $(9 \mathrm{~mm})$. This is in agreement with Ammara et al. (2009) who recorded highest susceptibility with Staphylococcus aureus $(17 \mathrm{~mm})$. She then concluded that the strong extraction capacity of ethanol could have been responsible for the higher antimicrobial activity. While in the aqueous extract, the highest antimicrobial activities were observed against Staphylococcus aureus $(11 \mathrm{~mm})$ and Pseudomonas aeruginosa $(8 \mathrm{~mm})$ showed least susceptibility to aqueous extract. In all, the methanolic extract showed the highest antimicrobial activities, followed by ethanol, while the lowest antimicrobial activity was observed in aqueous extract which might be due to insolubility of the active compounds in water. The antimicrobial effects of ethanol and methanol extracts against these organisms may be due to the ability of the ethanol and methanol to extract some of the active properties of these plants like saponins, alkaloids and other secondary metabolites which are reported to be antimicrobiological in nature (Adebanjo et al., 1983). Statistical analysis showed that these tested organisms showed significant differences $(\mathrm{p}<0.05)$ in their sensitivities to the plant extract.

Investigation of the antimicrobial activity of Citrus aurantifolia fruit juice has been investigated (Soforora 1996). Lime juice was found to have high zone of inhibition on Trichophyton rubrum (24 $\mathrm{mm}$ ) when concentrated. In this study, it was observed that the potency of lime fruit is enhanced by its concentration. The more concentrated the fruit juice, the more effective it becomes. This then shows that concentrated lime juice is very potent in the treatment of infectious diseases caused by this test organism. This is in correlation with Ibukun et al. (2007) who reported that Citrus aurantifolia fruit juice had activity on Candida albicans. This observation could be as a result of citric acid contained in the lime juice that was able to inhibit the growth of this fungus.

Antibiotic and antifungal drugs were used in this work as standard antimicrobials. It was found out that the ciprofloxacin used as the standard antibiotic had inhibitory effect on the test organisms with zone of inhibition ranging from 10 $\mathrm{mm}$ to $22 \mathrm{~mm}$ while the fluconazole used as the antifungal had appreciable effect on the fungus with zone of inhibition ranging from $15 \mathrm{~mm}$ to $18 \mathrm{~mm}$. This study is in agreement with the work of Akinnibosun and Edionwe (2015) who found out that ciprofloxacin had effect on the test bacteria. This study also agrees with the work of Al-Mohana, (2010) who reported that clotrimazole has effect on Candida albicans with inhibition zone of $18.8 \mathrm{~mm}$. This is also in agreement with Agarwal et al. (2010) who reported that fluconazole completely inhibited the growth of this organism. This is as a result of azole drugs having direct effect on the fatty acids of cell membranes thereby leads to the depletion of ergosterol in the membrane.

Phyto-chemicals are secondary metabolites of plants known to exhibit diverse pharmacological and biochemical effects on living organisms (Akinnibosun and Edionwe, 2015). The antimicrobial effects of these plant extracts are attributed to the phytochemical constituents present in it (Dawoud et al., 2013). These plant extracts are rich in phyto-nutrients such as flavonoids, tannins, saponins, glycosides, alkaloids, reducing sugars and steroids. These secondary metabolites exert antimicrobial activities through different mechanisms: It was reported that tannins are known to react with proteins to provide the typical tannins effect which is important for the treatment of inflamed or ulcerated tissues. Herbs that have tannins as their main components are astringent in nature and are used for the treatment of intestinal disorders such as diarrhea, dysentery and inflamed mucous membranes (Devbhuti et al.,2012). Flavonoids have biological function which includes protection against allergies, inflammation, free radicals, microbes, ulcers, hepatoxins, viruses and tumors (Castillo et al., 2000). This plant also contains alkaloids which are ranked the most efficient therapeutically significant plant substance. Pure isolated plant alkaloids and their synthetic derivatives are used as basic medicinal agents for their analgesic, antispasmodic and bacterial effects.

Conclusively, this study justifies the use of Citrus aurantifolia leaf extracts and fruit juice against microbial infections like skin infections, abscess and gastrointestinal disorder as well as ringworm caused by Trichophyton rubrum. The findings of this research showed that this plant can be considered in the development of new antimicrobial drugs and can be applied in different areas of research such as the pharmaceutical.

\section{References}

i. Adebanjo, A. O., Adewumi, C. O., Esien, E. E. (1983).Anti-infective agents of higher plants. 5th international symposium of medicinal plants. University of Ife, Nigeria, 152 - 158.

ii. Agarwal, V., Lai, P., Pruthi, V. (2010) . Effects of plant oils on Candida albicans. J Microbiol Immunol Infect,45 (5): $447-$ 451.

iii. Akinnibosun, F. I., Edionwe, O. (2015). Evaluation of the Phytochemical Antimicrobial potential of the leaf extracts of Bryophyllum pinnatum L. and Citrus aurantifolia Sw. and their Synergy.J Appl Sci Environ Manage, 19(4): 611-619.

iv. Albinu, I., Adenipekun, E., Odugbemi, T. (2004). Emergence of Quinolone Resistance amongst Escherichia coli strains isolated from clinical infections in some Lagos State Hospitals in Nigeria. Nig J Hlth Biomed Sci, 3(2); 73-78.

v. Albinu, I., Odugbemi, T., Mee, B. J. (2003). Extended-Spectrum Bete-Lactamases in Isolates of Klebsiella spp and Escherichia coli from Lagos, Nigeria. Nig J Hith Biomed Sci, 2(2): 53-60.

vi. Ammara, H, Salma, R., Farah, D., Shahid, M. (2009). Antimicrobial activity of some plant extracts having hepato protective effects. J Med Plant Res, 3(1):020-023.

vii. Banson, A. (2009). (Phytochemical and Antibacterial investigation of bark of Acacia nilatica. J Med Plants Res,3: 82-85.

viii. Bina, L. J., Tista, P., Anjana, S., Kayo, D. Y. (2010). Study of antimicrobial Activity of lime juice against Vibrio cholera. Scientific World, 8: 44-48. 
ix. Castillo, M. C., Allori, G. G., Gutierrez, R. C, Saan, O. A., Fernande, N. P., Ruiz, C. S.,Holgado, A. P., Nader, O. M.( 2000). Bactericidal activity of Lemon Juice and lemon derivatives against Vibrio cholera. Biol Pharma Bulletin, (10):1235-8.

x. Daquino, M., Teves, S. A. (1994). Bull Pan Am Health Organization University of Buesnos Aires, School of Pharmacy and Biochemistry, Argentina, 28(4):324-330.

xi. David, M. (1997). Antimicrobial activity of garlic. Antimicrob Agents and Chem,41: 2286.

xii. Dawoud, M. E. A.,Mawgoud, Y. A, Gouda, T. M. (2013). Synergistic interactions between plant extracts, some antibiotics and/ or their impact upon antibiotic-resistant bacteria isolates. Afri J Biotechnol, 12(24): 3835-3846.

xiii. Devbhuti, D., Gupta, K. K., Devbhuti, P. (2012). Studies on antitumour activity of Bryophyllum calycinum Salisb against Ehrlich ascites carcinoma in swiss albino mice.J Pharma Sci, 2(1):31 - 33.

xiv. Dingle, J., Red, W., Solomonas, G. L. (1953). The enzymatic degradation of pectin and other polysaccharides II. Application of Cup Assay Method to the Estimation of Enzyme. J Sci Food Agric, Pp. 149-153.

xv. Grabley, S., Thiericke, R. (1999). Drug Discovery from Nature. London: Springer: pp. 5-7.

xvi. Grosvenor, P. W., Supriono, A., Gray, D. O. (1995). Medicinal plants from Riau Province, Sumatra, Indonesia. Part 2, Antibacterial and Antifungal activity.J Ethopharma, 45: 97-111.

xvii. Ibukun, A., Tayo, A.,Toyin, A, Tolu, O. (2007). Evaluation of the Antimicrobial properties of Different parts of Citrus aurantifolia (Lime Fruit) as used Locally. Afri J Tradt Complement Altern Med,4(2): 185-190.

xviii. Jabeen, R., Ashraf, M., Ahmad, I. (2007). Evaluating the effects of cold water diffusates against Xanthomonas oryzae Pv. Oryzae causing bacterial leaf blight in rice. Phytopathol Plant Protect, 40: 1-9.

xix. Kayode, A. A., Kayode, O. T. (2011), Some medicinal values of Telfairia occidentalis: A review. Amer J Biochem MoleBiol, 1: 30-38.

xx. Khan, P. R., Gali, P. R., Pathan, P., Gowthan, T., Pasupuleti, S. (2012). In Vitro antimicrobial activity of Citrus aurantifolia and its phytochemical screening. Live Sciences feed, 1(2): 13 - 16.

xxi. Mata, L., Vargas, C., Saborio, D., Vices, M. (1994). Extinction of Vibrio cholerae inacidic substrata: Contaminated cabbage and Lettuce treated with lime juice. Rev J Biol Trop Studies,42(3):487-92.

xxii. Murugesan, S., Pannerselvan, A., Tangavelou, A. C. (2011). Phytochemical screening and antimicrobial activity of the leaves of Memecylon unbellatum burn. F. J. App. Pharm. Sci, 1: $42-45$.

xxiii. Odebiyi ,A,Sofow ora, A. E. (1978) .Phytochemical screening of Nigeria medicinal plant part II1. Lioydia, 4: $234-246$.

xxiv. Ogata, M, Hoshi, M, Urano, S, Endo, T. (2000). Antidudant activity of eugenol, and related monomeric and dimeric compounds. Chem. Pharm. Bull, 48:1467-1489.

xxv. Onuorah, S,Nriagu, O, Obika, I. (2016). Isolation, Characterization and Identification of Microorganisms from Spoilt Carrots obtained from Ose market, Nigeria. Universal J Biomed Eng, 4(1): 6-9.

xxvi. Onyeagba, R. A, Ugbogu, O. C, Okeke, C. U. Iroakasi, O. (2004). Studies on the antimicrobial effects of garlic (Allium sativum Linn), ginger (Zingiber officinale Roscoe) and Lime (Citrus aurantifolia Linn). Afri J Biotechnol,3(10):552-554.

xxvii. Robin, E.H, Anril, W, Alexander, M, Loeto, M, Keith, K. (1998). Nasopharyngeal carriage and antimicrobial resistance in isolates of Streptococcus pneumonia and Heamophilus influenzae Type b in children under 5 years of age inBotswana. Inter J Infect Dis, 3(1): 18-25.

xxviii. Sexena, K. (1997). Antimicrobial Screening of Selected Medical Plants from India.J. Ethnopharm, 58(2): 75-83.

xxix. Sofowora, A. (1996) .Medicinal plants and traditional medicines in Africa. Spectrum Books, Ibadan, Nigeria:,pp 112.

xxx. Tallarida, J. R. (2001). Drug synergism: Its detection and applications. Pharma,298: 865-872.

xxxi. Tomotake, H, Koga T, Yamato, M, Kassu, A, Ota, F. (2006). Antimicrobial Activity of citrus fruits juices against Vibrio species. Iida Women's JuniorCollege, Nagana, Japan. Nutri Sci Vitamin, 52(2):157-160.

xxxii. Tshesche, R. (1970). Advances in the chemistry of antibiotic substances from higher plants: pharmacogency and phytochemistry. In proceedings of the 1 st international congress, Munich.

xxxiii. World Health Organization (WHO). (1977) .(Resolution-promotion and development of training and research in traditional medicine). WHO Document, 30: 49 - 50. 